\title{
The chronically ill patients' quality of counselling in the hospital
}

\author{
Pirjo Kaakinen $^{1,2}$, Maria Kääriäinen ${ }^{1}$, Helvi Kyngäs ${ }^{1}$ \\ 1. Institute of Health Sciences, University of Oulu, Finland. 2. University hospital of Oulu, Finland.
}

Correspondence: Pirjo Kaakinen. Address: University of Oulu, Institute of Health Sciences. Aapistie 5A Box 5000, 90014 University of Oulu, Finland. Telephone: 35-840-750-8056. Fax: 35-885-375-111. E-mail: pirjo.kaakinen@oulu.fi

Received: January 30, 2012

DOI : 10.5430/jnep.v2n4p114

\section{Abstract}

Background: Patient counseling is one of the core elements in healthcare. The number of chronically ill people is increasing, whilst the number of additional stays in hospital that are required has dropped. Thus, there is less time to deliver good-quality patient counseling when they are in hospital. The aim of this study was to describe quality of patient counseling chronically ill patients' in the hospital.

Methods: This study used a cross-sectional design. A convenience sample $(\mathrm{n}=106)$ of patients, who had suffered ischemic attack, COPD or cardiac disease was employed. Data were collected using the Counseling Quality Instrument (CQI) questionnaire.

Results: Most chronically ill people received patient counseling about their disease symptoms, but there was lack of content of counseling about social support and the disease prediction. Half of the patients reported that their counseling had been implemented in planned manner and that they had experienced positive interaction during that counseling. Sixty percent of chronically ill patients had perceived patient counseling about the result of investigations, but half of respondents did not receive patient-centered counseling. Patient counseling had a positive benefit on the treatment of the chronically ill and their attitudes. Eighty percent of the patients were satisfied with the counseling materials and methods. Those over 60 years old and those who lived alone were the most dissatisfied with patient counseling.

Conclusion: The findings indicate that chronically ill patients' counseling on social support and disease prediction require development. In addition, implementation of patient counseling should be more patient-centered and based on care plan.

\section{Key words}

Counseling, Patient education, Chronic illness, Hospital patient

\section{I ntroduction}

People with chronic disease need patient counseling to help them manage their disease in their everyday life ${ }^{[1,2]}$. This is a challenge for healthcare staff because the number of chronically ill people is increasing, whilst the number of additional stays in hospital that are required has dropped ${ }^{[3,4]}$. Thus, there is less time to deliver good-quality patient counseling when they are in hospital. There have been numerous studies into the nature of counseling that chronically ill patients receive ${ }^{[2,5-10]}$. Nevertheless, little attention has been paid to the quality of patient counseling among chronically ill patient. 
There is no generally accepted definition of good-quality of patient counseling ${ }^{[5,11-16]}$. Based on earlier literature, the quality of patient counseling is related to content, implementation and benefits of patient counseling as well as counseling materials and methods ${ }^{[13,14]}$.

In the hospital, counseling patients about their disease and its symptoms ${ }^{[9,17-20]}$ was consider essential to allow the chronically ill to care for themselves at home and be able to deal with other related medical problems ${ }^{[1,19,21,22]}$. There are a several benefits from patient counseling such as increased knowledge about disease and treatment ${ }^{[5,17,23,24]}$. Although the chronically ill have unique patient counseling needs from each other, they all need to learn about social support ${ }^{[9,14]}$, in particular emotional support and social benefits, from healthcare staff ${ }^{[1,20,25-27]}$, family members and peers ${ }^{[9,20,28]}$.

Patient counseling that has been planned is implemented in a patient-centered way. It takes into account the background of the chronically ill, including how much they already know about the disease, lifestyle and emotional health ${ }^{[14,29,30]}$. The needs for knowledge were mainly directed towards the disease and its symptoms ${ }^{[9,17-20]}$, but there were studies consider chronically ill patients' knowledge of progression of their disease and the future ${ }^{[31,32]}$. It means also that interaction during counseling is encouraged and confidential ${ }^{[14,31,33]}$. Within the confidential environment allows the chronically ill to ask questions $^{[7,9,20]}$ and have interactive support to help discuss emotional issues with healthcare staff ${ }^{[9,15,34]}$.

A goal-oriented counseling is planned beforehand ${ }^{[26,35,36]}$. Planned patient counseling take account of the needs of patients ${ }^{[1,8,23]}$ and created opportunities to receive feedback on how prepared a patient feels to care for themselves. As patient counseling is planned, both the individual needs of the chronically ill ${ }^{[7,32,35,36]}$ and the different ways in which individuals learn are considered ${ }^{[7,35]}$. Counseling strategies can then be developed to best suit the patients ${ }^{[7,32,35,36]}$.

The good-quality of patient counseling has been implemented using the methods, which emphasizes chronically ill patients' ability to manage their disease. Suitable counseling materials, methods and time set aside for counseling, as well as competent healthcare staff, are some of the core elements of patient counseling ${ }^{[14,29,35,37]}$.

Several differences are exist between cultural backgrounds of chronically ill patients' counseling. There are countries, which the chronically ill patient counseling based on "Chronic care Model” [38, 39]. In Finland, the structure and solution of patient counseling vary from planned counseling to random question and answering counseling session. In Finland, the content of patient counseling is, in part, governed by legislation and patients have the right to know about their health, the aims of their treatment, alternative treatments available, the effects of the treatment on their everyday lives and other issues that concern the care of the chronically ill ${ }^{[40]}$. In Finnish healthcare, typically patient counseling consist of the following items; knowledge of disease and treatment, medication, complications, follow-up and daily living such as nutrition, physical activity ${ }^{[5-7,9,14]}$. Also, patients want knowledge of social support ${ }^{[6,14]}$. Chronically ill patients' counseling is typically conducted orally by the nurses and written material support counseling ${ }^{[7-9,14]}$, rarely use multimedia ${ }^{[27]}$. Usually, the chronically ill patient has a number of medications in use and it is not always clear how they used medication at home, so it is relevant to discuss and counsel about medication ${ }^{[41]}$.

As is known, the patients' active participation in treatment is strengthening the positive results of the care ${ }^{[8,14,23,24,42]}$. However, chronically ill patients have different counseling requirements in relation to their disease and their knowledge of the disease varied; consequently, they may have conflicting views to those of healthcare staff concerning which parts of patient counseling are important ${ }^{[6,8,9]}$.

The aim of this study was to describe quality of patient counseling chronically ill patients' in the hospital. This is important issue to study, because to improve the chronically ill adults' patient counseling, we need to know what kind patient counseling is when chronically ill patients are discharged. 


\section{Methods}

\subsection{Design}

This study used a cross-sectional, descriptive design and was conducted using a questionnaire administered at the university hospital and the central hospital in Northern Finland. These hospitals expressed their willingness to participate in the research because they were interested in developing patient counseling by educating the nurses and developing content.

The Counseling Quality Instrument (CQI) was used; this has been developed to determine the quality of patient counseling ${ }^{[14]}$ and covers four main areas. It consists of eight background questions. The CQI has 84 items covering the following areas: "content of counseling” (24 items), "implementation of counseling” (33 items), "benefit of counseling" (17 items), and "counseling materials and methods" (10 items). For example, "content of counseling” includes: symptoms, disease risk factors and medication. "Implementation of counseling” was measured with items concerning patients' needs, interaction and goal-oriented counseling. "Benefit of counsel” includes: knowledge of disease and self-care. "Counseling materials and methods" includes: time spent on counseling, counseling materials and counseling skills. The responses for all four areas were measured using a 5-point Likert scale ranging from one (strong disagreement) to five (strong agreement) ${ }^{[14]}$.

The CQI validity and reliability are considered good. Cronbach's alpha values (0.8-0.9) indicate high internal consistency of the instrument ${ }^{[7,14]}$.

\subsection{Data collection}

This study was part of larger study for chronically ill adults' patient counseling. The first phase was made an integrative literature review of chronically patient counseling in healthcare setting and the purpose of this study was to describe chronically patients' counseling in the hospital.

The study sample consisted of voluntary adults ( $\mathrm{n}=106)$, who were treated in central hospital or university hospital during the period May to September 2010. In Finland, data collection was performed during a five month period, because June and July were holiday months. The inclusion criteria were patients diagnosed an ischemic attack, chronic obstructive pulmonary disease (COPD) or cardiac disease, were Finnish speaking and 18 years of age or older. There was no limitation of duration of disease or frequency of visit in the hospital. Patients with diagnosed mental disorders such as schizophrenia, dementia or serious memory disorder were excluded.

Non probability sampling was used and nurses whom the patients met during their hospital visits in research units or researcher invited chronically ill patient who met inclusion criteria to participate in the study. The nurses or researcher shared information sheet about the study. After a decision on their discharge had been made and chronically ill patient expressed to willingness to participate $(\mathrm{N}=240)$, the nurses in the research units or the researcher distributed a questionnaire. None of the participants invited to participate refused to complete the questionnaire. Patients' were not required to sign the consent form.

The questionnaire was distributed after a decision on discharge had been made, to ensure that the patients had received patient counseling of the disease and treatment. The questionnaire could either be completed in hospital before discharge or at home and then posted to the researcher.

One hundred and ten questionnaires were returned, of which four questionnaires were rejected; because less than $50 \%$ of the questions had been answered. The patients filled in the questionnaires anonymously, so it was impossible to request the respondents concerned to re-submit their answers. 


\subsection{Ethical considerations}

The study was approved by the Medical Director of the two hospitals. In Finland, according to the Medical Research Act (488/1999) and amendments to this law (295/2004), this kind of study does not require the approval of the ethical committee of healthcare organisations. Information about study was available for the research units. All respondents received the covering letter, it was emphasized that participation in the study was voluntary. Participants' names and other identifiers were not recorded during the study. The participants returned their questionnaires either in a sealed envelope by mail or in a sealed box at the sites where the research was carried out. The respondents were given the opportunity to obtain additional information was given in the covering letter. All data were kept in a locked cabinet and will be disposed of appropriately.

\subsection{Data analysis}

Predictive Analytics Software (PASW Statistics, version 18.0) was used for data analysis. Background information was examined using descriptive statistics and missing values were replaced by the average of the value from patients with the same disease. A principal component analysis (PCA) was carried out in order to analyze the relationship between to group the large numbers of variables ${ }^{[43]}$. Sum variables were constructed based on PCA, the results of which were similar to previous studies ${ }^{[7,14]}$. Thus, sum variables could be identified according to the content of the factors.

Three sum variables were identified from the "content of patient counseling" variables: knowledge of the symptoms, social support and the results of investigations into their condition. From the "implementation of counseling" variables, four sum variables were identified: planning of patients' counseling, interaction with the counseling, patient-centered counseling and disease prediction. From the "benefits of counseling" variables, two sum variables were identified: impact of patients' disease treatment and impact of patient' attitudes. One sum variable belonged to the variables associated with "counseling materials and methods".

The Cronbach's alpha values varied between 0.77 and 0.95 . The sum variables of the amount of the items, their alpha values and total variances are listed in Table 1. Nine items were excluded from the sum variables because of low commonalities. Sum variables were categorized into two groups based on mean, histogram and boxplot. The values $1.00-$ 2.24 presented poor patient counseling and 2.25 - 5.00 good patient counseling.

Table 1. Sum variables, amount of items, Cronbach's alpha values and total variance

\begin{tabular}{|c|c|c|c|}
\hline Sum variable name & Amount of items & Cronbach's alpha & Total variance $(\%)^{*}$ \\
\hline The content of patient counseling & & & 66.7 \\
\hline Knowledge of the symptoms & 12 & 0.94 & \\
\hline Social support & 4 & 0.86 & \\
\hline Results of the investigations & 4 & 0.86 & \\
\hline Implementation of counseling & & & 68.9 \\
\hline Planning of the patient counseling & 12 & 0.95 & \\
\hline Interaction of the counseling & 7 & 0.93 & \\
\hline Patient-centered patient counseling & 10 & 0.92 & \\
\hline Disease prediction & 2 & 0.77 & \\
\hline The benefit of counseling & & & 71.2 \\
\hline Impact of patients' disease treatment & 8 & 0.94 & \\
\hline Impact of patients' attitudes & 7 & 0.91 & \\
\hline Counseling materials and methods & 10 & 0.92 & 62.6 \\
\hline
\end{tabular}

*Principal component analysis

Differences between background variables and sum variables were studied using the Pearson correlation coefficient test and the Chi-Square test. Differences in the mean scores between groups (background and sum variables) were tested using 
a $t$-test when there was an approximately normal distribution or a Mann-Whitney U-test when the data were not normally distributed. The results presented are statistically significant $(p<0.05)$.

\section{Results}

Thirty-eight percent of respondents suffered from ischemic attacks, 34\% had heart failure and almost one third (28\%) suffered from COPD. Sixty-five percent of the participants were male and had a mean age of 64 years. About half of the respondents (55\%) were married or lived with someone. Over half of the respondents (54\%) had completed elementary education. Fifty-nine percent of respondents had suffered chronic disease for less than five years. The majority of the participants were treated at the university hospital (78\%) and were referred to the hospital as emergency cases (75\%). The background information of the participants are shown in table 2 .

Table 2. Background information of the participants $(\mathrm{n}=106)$.

\begin{tabular}{|c|c|c|}
\hline Characteristics & $f$ & $\%$ \\
\hline \multicolumn{3}{|l|}{ Sex } \\
\hline Female & 36 & 35 \\
\hline Male & 67 & 65 \\
\hline \multicolumn{3}{|l|}{ Age (years)* } \\
\hline$<55$ & 27 & 26 \\
\hline $55-70$ & 47 & 44 \\
\hline$>70$ & 32 & 30 \\
\hline \multicolumn{3}{|l|}{ Marital status } \\
\hline Single & 11 & 11 \\
\hline Live together/married & 57 & 55 \\
\hline Divorced & 18 & 17 \\
\hline Widow & 18 & 17 \\
\hline \multicolumn{3}{|l|}{ Education level } \\
\hline Elementary education & 56 & 54 \\
\hline Vocational education & 39 & 38 \\
\hline University education & 8 & 8 \\
\hline \multicolumn{3}{|l|}{ Diagnosis } \\
\hline COPD & 30 & 28 \\
\hline Cardiac failure & 36 & 34 \\
\hline Ischemic attack & 40 & 38 \\
\hline \multicolumn{3}{|c|}{ Duration of disease in years** } \\
\hline$<5$ years & 63 & 59 \\
\hline 5-10 years & 20 & 19 \\
\hline$>10$ years & 23 & 22 \\
\hline \multicolumn{3}{|l|}{ Hospital type } \\
\hline Central hospital & 23 & 22 \\
\hline University hospital & 83 & 78 \\
\hline \multicolumn{3}{|l|}{ Visit type } \\
\hline Emergency visit & 74 & 75 \\
\hline Planned admission & 25 & 25 \\
\hline
\end{tabular}

*Mean age 64 years (SD =12.4, range 26-91 years)

**Duration of disease mean 5 years $(\mathrm{SD}=6.29$, range 0 -30 year)

\subsection{Content of patient counseling}

The "content of patient counseling" focused on the knowledge of symptoms, social support and the results of investigations into a patient's condition. The majority of respondents (68\%) received adequate information about 
symptoms, but they wanted to know more about social support. Three quarters of the respondents (75\%) had a poor knowledge of social support and, for $41 \%$ of the respondents, the explanation of the results of investigations was unsatisfactory.

The results of the investigations had a negative correlation with the respondents' type of hospital visit $(r=-0.301, p=$ 0.002). Respondents who came to the hospital emergency room were more satisfied with patient counseling regarding the results of the investigation than respondents who were admitted to hospital ( $\mathrm{U}=608.500, p=0.003$ ) (see Table 3).

Table 3. The sum variables measuring quality of patient counseling and statistically significant $(p<0.05)$ background variables $(\mathrm{n}=106)$

\begin{tabular}{|c|c|c|c|c|c|c|}
\hline \multirow{2}{*}{ Sum variable } & \multicolumn{2}{|c|}{ Good } & \multicolumn{2}{|c|}{ Poor } & \multirow{2}{*}{ Background variable } & \multirow{2}{*}{$p$} \\
\hline & $\mathbf{N}$ & $\%$ & $\mathrm{n}$ & $\%$ & & \\
\hline \multicolumn{7}{|l|}{ The content of patient counseling } \\
\hline Knowledge of the symptoms & 72 & 68 & 34 & 32 & & \\
\hline Social support & 27 & 25 & 79 & 75 & & \\
\hline Results of the investigations & 63 & 59 & 43 & 41 & Type of visit ${ }^{\dagger}$ & 0.003 \\
\hline \multicolumn{7}{|l|}{ Implementation of counseling } \\
\hline Planning of the patient counseling & 53 & 50 & 53 & 50 & & \\
\hline Interaction of the counseling & 82 & 77 & 24 & 23 & Type of hospital ${ }^{\ddagger}$ & 0.033 \\
\hline Patient-centered patient counseling & 41 & 39 & 65 & 61 & & \\
\hline Disease prediction & 39 & 37 & 67 & 63 & Marital status ${ }^{\ddagger}$ & 0.02 \\
\hline \multicolumn{7}{|l|}{ The benefit of counseling } \\
\hline Impact of the patient disease treatment & 86 & 81 & 20 & 19 & & \\
\hline Impact of the patients' attitude & 72 & 68 & 34 & 32 & $\operatorname{Age}^{\ddagger}$ & 0.021 \\
\hline Counseling materials and methods & 85 & 81 & 21 & 20 & $\mathrm{Age}^{\dagger}$ & 0.011 \\
\hline
\end{tabular}

$\dagger$ Mann-Whitney U-test; $\ddagger t$-test; $\ddagger$ Chi-Square test

Patients over 60 years old and those, who lived alone (38\%) were not satisfied with their knowledge of the symptoms. Respondents who had suffered from their disease for more than five years (81\%), or were over 60 years old (78\%) or who lived alone (79\%) considered their counseling about social support to have been unsatisfactory. Respondents aged over 60 year (63\%) were satisfied that they had received good information about the results of investigations was good.

\subsection{I mplementation of counseling}

"Implementation of counseling" includes the planning of patient counseling, interaction during counseling, patient-centered counseling and disease prediction. Half of the respondents (50\%) reported that their counseling had been planned. One in four (23\%) felt that interaction during counseling was not encouraged and more than half of the respondents (61\%) had not received patient-centered counseling. Thirty-seven percent of the respondents had received information about how their disease was expected to progress. There were positive correlations between respondents' marital status and disease prediction $(r=0.22, p=0.022)$. Respondents who lived with someone or were married were happier with their knowledge of how their disease was expressed to progress than those who lived alone $(t=2.36, p=$ 0.020) (see Table 3).

There was a statistically positive correlation between the hospitals where respondents were studied for this research and quality of counseling interaction ( $r=0.21, p=0.033$ ). Those respondents who were treated in the university hospital expressed counseling as a pleasant interaction as opposed to those who were in the central hospital $\left(\chi^{2}=4.56, p=0.033\right)$ 
(see Table 3). Both genders regarded the planning of counseling (50\%), patient-centered counseling (61\%) and disease prediction (men $66 \%$ and women $58 \%$ ) as insufficient.

\subsection{The benefit of counseling}

The "benefit of counseling" includes the impact on patients' medical treatment and patients' attitudes. Patient counseling had many positive influences on the patients' self-care. Most of the respondents (81\%) reported complying with their medical treatment; they also felt that counseling helped them to have better knowledge of healthy eating. Furthermore, their physical activity and responsibility towards managing their disease also increased. The majority of the respondents (68\%) felt that patient counseling had influenced their attitudes towards chronic disease. There were negative correlations between respondents' age and attitudes towards their illness $(r=-0.214, p=0.028)$. Those who were under 60 years old experienced a more positive impact on their attitudes towards their illness than older patients $(t=-2.34, p=0.021)$ (see Table 3).

\subsection{Counseling materials and methods}

Most of the respondents (80\%) were satisfied with the counseling resources. The counseling materials and methods such as counseling time, materials, methods and the staff education skills. There were positive correlations between counseling resources and the respondents' age $(r=-0.25, p=0.010)$. Those over 60 years were more dissatisfied with counseling materials and methods than younger respondents $(\mathrm{U}=1061.00, p=0.011)$ (see Table 3).

\section{Discussion and conclusion}

\subsection{Discussion}

According to this study, chronically ill patients received adequate patient counseling about the content of patient counseling such as symptoms and results of the investigations during their hospital visit as previous studies have shown ${ }^{[1,5,23,24]}$. The chronically ill who came to hospital via the emergency room were more satisfied with the patient counseling regarding the results of investigations. This was surprising and may illustrate the fact that respondents received more patient-centered counseling in the emergency room and had more individual instruction than those who had had a planned admission to hospital.

More knowledge is needed into the information on social support given by the healthcare staff, as studied in previous research ${ }^{[9,20,44]}$. Most of the respondents received patient counseling on social support poorly according this study. To ensure good patient counseling in hospital, the healthcare staff needs counseling how to deliver social support for chronically ill. It is know, that patients' who received social support followed their treatment regimen and medication more closely.

The good quality of patient counseling is planned and it should be implemented patient-centered. However, this study has shown that implementation of patient-centered counseling and planning of counseling during hospital treatment were both poor. The chronically ill patients' context should be start point for patient counseling, so that their problems concerning disease could be solved. This is actually important, because patient-centered counseling provides the chronically ill with active participation in their treatment and strengthens compliance ${ }^{[23,42]}$. Evaluation is much easier if a chronically ill patient has a care plans with set goals. To ensure good implementation of patient counseling is essential confidential interaction, which was seen as a chronically ill according to this study better in university hospital than central hospital in this study.

Although chronically ill patients' have received good information symptoms, they have reported how important it is to receive counseling on disease prediction ${ }^{[18,44]}$. However, in this study, only one third reported that they had received such 
information. This may have results of uncoordinated care between university hospital and primary care and sometimes it may be difficulty for healthcare staff to prognosticate accurately. In some cases, there were the lack of understand received information about disease prediction process and there were fear discussion about future by chronically ill patients'. However, more attention should be paid chronically ill patients' counseling of disease prediction process according this study. It may be easier to discuss disease prediction process, if the chronically ill patients' care were planned and based on patients' needs.

The good quality of patient counseling means that counseling of the chronically ill has a distinct benefit of chronically ill patients' self-care and their attitudes towards that disease. The results of earlier studies support this finding ${ }^{[15,31]}$. According this study, younger chronically ill patients was satisfied patient counseling benefiting their attitudes than older people. These study patient counseling resources were good, such as counseling materials and materials, even though older respondents were not so satisfied counseling resources than younger.

It is remarkable that this study the most of chronically ill patients' were older than 60 -years and were male. They were hospital as an emergency case. Consequently, healthcare staff should pay attention to how they design counseling sessions for the elderly chronically ill patients' and those how lived alone.

\subsection{Study limitations}

The sample was small and mostly comprised chronically ill patients who had been hospitalized as emergency cases and treated at the university hospital. So many of the respondents were seriously ill at the time of the study, and additional summer time may have affected the results. Nevertheless, the study provides important information about the focus of patient counseling.

In addition, in this study most of the respondents had a low level of education and were elderly (mean 64 years). Therefore, they may have had difficulties with filling in the questionnaire and this may be the reason for them dropping out of the study. Patients who had suffered ischemic attack were the worst at correctly filling questionnaires.

There may also be a possible bias caused by subjects responding with what they believed to be socially acceptable answers as usually in survey studies. This study was conducted in two hospitals in Northern Finland and therefore generalization of the results is limited. Moreover, the sample making up the study population was non-random and there were only a few women who participated in the study.

Even though there are some limitations to this study, its strengths lie in the fact that the data were collected using a recognized instrument with a high degree of validity and high reliability. Furthermore, in this study principal component analysis indicated good construct validity, whilst the Cronbach's alphas values showed good internal consistency (0.77 0.95). In efforts to reduce the drop-out, nurses and researchers distributed the questionnaire and encourage respondents to fill it. In addition, the respondents also had the opportunity to contact the researcher for additional information concerning the study.

\subsection{Conclusion}

The result of this study cannot be generalized, but the chronically ill were relatively satisfied with quality of patient counseling provided by healthcare staff in the hospital. However, there are issues with the explanation of the social support available and counseling regarding disease prediction. The implementation of counseling for the chronically ill patients needs to be moved towards patient-centered and planned counseling. In addition, those over 60 years of age and those who live alone have counseling requirements that warrant particular attention.

\section{Acknowledgement}

We would like to thank the Attractive and Health-promoting Healthcare project for support (Finnish VeTe- project). 


\section{References}

[1] Barlow JH, Cullen LA, Rowe LF. Educational preferences, psychological well-being and self-efficacy among people with rheumatoid arthritis. Patient Educ Couns. 2002; 46: 11-9. http://dx.doi.org/10.1016/S0738-3991(01)00146-X

[2] Boren SA, Wakefield BJ, Gunlock TL, Wakefield DS. Heart failure self-management education: a systematic review of the evidence. INT J EVID BASED HEALTHC. 2009; 7: 159-68. PMid:21631856 http://dx.doi.org/10.1111/j.1744-1609.2009.00134.x

[3] Word Health Organization. Chronic disease [Internet]. 2010. Available from: http://www.who.int/topics/chronic_diseases/en/ (accessed November 2011).

[4] The National Institute for Health and Welfare. Statistical yearbook on social welfare and health care [Interent]. 2011. Available from: http://www.thl.fi/thl-client/pdfs/aab19516-a923-42e9-9430-fa2564c504d0 (assessed February 2012).

[5] Leino-Kilpi H, Johansson K, Heikkinen K, Kaljonen A, Virtanen H, Salantera S. Patient education and health-related quality of life: surgical hospital patients as a case in point. J Nurs Care Qual. 2005; 20: 307-16. PMid:16177581 http://dx.doi.org/10.1097/00001786-200510000-00005

[6] Makelainen P. Rheumatoid Arthritis Patient Education and Self-Efficacy. Doctoral dissertation. Social Sciences 167. University of Kuopio. Kuopio, 2008.

[7] Kaariainen M, Kyngas H. The quality of patient education evaluated by the health personnel. Scand J Caring Sci. 2010 ; $24: 548-56$. PMid:20409053 http://dx.doi.org/10.1111/j.1471-6712.2009.00747.x

[8] Kaariainen M, Kukkurainen ML, Kyngas H, Karppinen L. Improving the quality of rheumatoid arthritis patients' education using written information. Musculoskelet care. 2011; 9: 19-24. PMid:21351366 http://dx.doi.org/10.1002/msc.192

[9] Lunnela J, Kaariainen M, Kyngas $H$. The views of compliant glaucoma patients on counselling and social support. Scand J Caring Sci. 2010; 24: 490-8. PMid:20210901 http://dx.doi.org/10.1111/j.1471-6712.2009.00739.x

[10] Tzeng L, Chiang L, Hsueh K, Ma W, Fu L. A preliminary study to evaluate a patient-centred asthma education programme on parental control of home environment and asthma signs and symptoms in children with moderate-to-severe asthma. J Clin Nurs. 2010; 19: 1424-33. PMid:20500352 http://dx.doi.org/10.1111/j.1365-2702.2009.03021.x

[11] Visser A, Deccache A, Bensing J. Patient education in Europe: united differences. Patient Educ Couns. 2001; 44: 1-5. http://dx.doi.org/10.1016/S0738-3991(01)00111-2

[12] Stromberg A. The crucial role of patient education in heart failure. Eur J Heart Fail. 2005; 7: 363-9. PMid:15718176 http://dx.doi.org/10.1016/j.ejheart.2005.01.002

[13] Johansson K, Salantera S, Katajisto J. Empowering orthopaedic patients through preadmission education: results from a clinical study. Patient Educ Couns. 2007; 66: 84-91. PMid:17161934 http://dx.doi.org/10.1016/j.pec.2006.10.011

[14] Kaariainen M. The Quality of Counselling: The Development of a Hypothetical Model [Finnish]. Acta Universitatis Ouluensis D 937. Oulu University Press, Oulu, 2007

[15] Sahlsten MJ, Larsson IE, Sjostrom B, Lindencrona CS, Plos KA. Patient participation in nursing care: towards a concept clarification from a nurse perspective. J Clin Nurs. 2007; 16: 630-7. PMid:17402943 http://dx.doi.org/10.1111/j.1365-2702.2006.01660.x

[16] Sigurdardottir AK, Jonsdottir H. Empowerment in diabetes care: towards measuring empowerment. Scand J Caring Sci. 2008; 22: 284-91. PMid:18298619 http://dx.doi.org/10.1111/j.1471-6712.2007.00506.x

[17] Johansson K, Salantera S, Katajisto J, Leino-Kilpi H. Patient education in orthopaedic nursing. J ORTHOP NURS. $2002 ; 6$ : $220-6$. http://dx.doi.org/10.1016/S1361-3111(02)00094-8

[18] Laerum E, Indahl A, Skouen JS. What is "the good back-consultation"? A combined qualitative and quantitative study of chronic low back pain patients' interaction with and perceptions of consultations with specialists. J Rehabil Med. 2006 ; 38: 255-62. PMid:16801209

[19] Smith J, Liles C. Information needs before hospital discharge of myocardial infarction patients: a comparative, descriptive study. J Clin Nurs. 2007; 16: 662-71. PMid:17402947 http://dx.doi.org/10.1111/j.1365-2702.2006.01689.x

[20] Linnarsson JR, Bubini J, Perseius KI. A meta-synthesis of qualitative research into needs and experiences of significant others to critically ill or injured patients. J Clin Nurs. 2010; 19: 3102-11. PMid:20738453 http://dx.doi.org/10.1111/j.1365-2702.2010.03244.x

[21] Granger BB, Sandelowski M, Tahshjain H, Swedberg K, Ekman I. A qualitative descriptive study of the work of adherence to a chronic heart failure regimen: patient and physician perspectives. J Cardiovasc Nurs. 2009; 24: 308-15. PMid:19465865

[22] Carpenter DM, DeVellis RF, Fisher EB, DeVellis BM, Hogan SL, Jordan JM. The effect of conflicting medication information and physician support on medication adherence for chronically ill patients. Patient Educ Couns. 2010; 81: 169-76.

PMid:20044230 http://dx.doi.org/10.1016/j.pec.2009.11.006 
[23] Gambling T, Long AF. The realisation of patient-centred care during a 3-year proactive telephone counselling self-care intervention for diabetes. Patient Educ Couns. 2010; 80: 219-26. PMid:20006458 http://dx.doi.org/10.1016/j.pec.2009.11.007

[24] Briggs LA, Kirchhoff KT, Hammes BJ, Song MK, Colvin ER. Patient-centered advance care planning in special patient populations: a pilot study. J Prof Nurs. 2004; 20: 47-58. PMid:15011193 http://dx.doi.org/10.1016/j.profnurs.2003.12.001

[25] Bergvik S, Wynn R, Sorlie T. Nurse training of a patient-centered information procedure for CABG patients. Patient Educ Couns. 2008; 70: 227-33. PMid:18078733 http://dx.doi.org/10.1016/j.pec.2007.10.013

[26] Shigaki CL, Moore C, Wakefield B, Campbell J, LeMaster J. Nurse partners in chronic illness care: patients' perceptions and their implications for nursing leadership. Nurs Adm Q. 2010; 34: 130-40. PMid:20234247

[27] Lunnela J, Kaariainen M, Kyngas H. Adherence of Finnish people with glaucoma to treatment plans and connected factors. INT J CIRCUMPOLAR HEALTH. 2011; 70: 79-89. PMid:21062571 http://dx.doi.org/10.3402/ijch.v70i1.17796

[28] Macdonald W, Rogers A, Blakeman T, Bower P. Practice nurses and the facilitation of self-management in primary care. J Adv Nurs. 2008; 62: 191-9. PMid:18394031 http://dx.doi.org/10.1111/j.1365-2648.2007.04585.x

[29] Harding R, Selman L, Beynon T, Hodson F, Coady E, Read C, et al. Meeting the communication and information needs of chronic heart failure patients. J Pain Symptom Manage. 2008; 36: 149-56. PMid:18599259 http://dx.doi.org/10.1016/j.jpainsymman.2007.09.012

[30] Nagelkerk J, Reick K, Meengs L. Perceived barriers and effective strategies to diabetes self-management. J Adv Nurs. 2006; 54: 151-8. PMid:16553701 http://dx.doi.org/10.1111/j.1365-2648.2006.03799.x

[31] Zakrisson AB, Hagglund D. The asthma/COPD nurses' experience of educating patients with chronic obstructive pulmonary disease in primary health care. Scand J Caring Sci. 2010; 24: 147-55. PMid:19691488 http://dx.doi.org/10.1111/j.1471-6712.2009.00698.x

[32] Iversen M, Hanestad B. Educational needs, metabolic control and self-reported quality of life: a study among people with type 2 diabetes treated in primary health care. EUR DIABETES NURS. 2005; 2: 11-16. http://dx.doi.org/10.1002/edn.12

[33] Robinson L, Bamford C, Briel R, Spencer J, Whitty P. Improving patient-centered care for people with dementia in medical encounters: an educational intervention for old age psychiatrists. Int Psychogeriatr. 2010; 22: 129-38. PMid:19615123 http://dx.doi.org/10.1017/S1041610209990482

[34] Hagberth V, Sjoberg T, Ivarsson B. Older women with a serious cardiac event experience support with a Vifladt \& Hopen inspired patient group education programme. Eur J Cardiovasc Nurs. 2008; 7: 140-6. PMid:17962079 http://dx.doi.org/10.1016/j.ejcnurse.2007.09.003

[35] Lundh L, Rosenhall L, Tornkvist L. Care of patients with chronic obstructive pulmonary disease in primary health care. J Adv Nurs. 2006; 56: 237-46. PMid:17042803 http://dx.doi.org/10.1111/j.1365-2648.2006.04027.x

[36] Cooper K, Smith BH, Hancock E. Patients' perceptions of self-management of chronic low back pain: evidence for enhancing patient education and support. Physiotherapy. 2009; 95: 43-50. PMid:19627685 http://dx.doi.org/10.1016/j.physio.2008.08.005

[37] Gardiner C, Gott M, Small N, Payne S, Seamark D, Barnes S, et al. Living with advanced chronic obstructive pulmonary disease: patients concerns regarding death and dying. Palliat Med. 2009; 23: 691-7. PMid:19825897 http://dx.doi.org/10.1177/0269216309107003

[38] Baker D, Asch S, Keesey J, Brown J, Chan K, Joyce G, et al. Differences in education, knowledge, self-management activities, and health outcomes for patients with heart failure cared for under the chronic disease model: the improving chronic illness care evaluation. J.CARD.FAIL. 2005; 11: 405-13. PMid:16105630 http://dx.doi.org/10.1016/j.cardfail.2005.03.010

[39] Loring K, Ritter P, Plant K. A disease-specific self-help program compared with a generalized chronic disease self-help program for arthritis patients. ARTHRITIS RHEUM. 2005; 53: 950-7. http://dx.doi.org/10.1002/art.21604

[40] Act on the Status and Right of Patients 785/1992. Available from: http://www.finlex.fi/laki/smur/1992/19920785

[41] Kyngas H. Compliance of adolescents with chronic disease. J Clin Nurs. 2000: 9; 549-56. PMid:11261135 http://dx.doi.org/10.1046/j.1365-2702.2000.00368.x

[42] Hoglund AT, Winblad U, Arnetz B, Arnetz JE. Patient participation during hospitalization for myocardial infarction: perceptions among patients and personnel. Scand J Caring Sci. 2010; 24: 482-9. PMid:20230518 http://dx.doi.org/10.1111/j.1471-6712.2009.00738.x

[43] Polit D, Beck C. Nursing research: generating and assessing evidence for nursing practice. 9th edn. 2011. Wolters Kluwer Health /Lippincott Williams \& Wilkins. Philadelphia, USA.

[44] Ågard A, Hermeren G, Herlitz J. When is a patient with heart failure adequately informed? A study of patients' knowledge of and attitudes toward medical information. Heart \& Lung. 2004; 33: 219-26. PMid:15252411 